\title{
Learning Potentials of Job Shadowing in Teacher Education
}

\author{
Makovec Danijela \\ Faculty of Arts, University of Ljubljana, Ljubljana, Slovenia \\ https://orcid.org/0000-0002-8077-3446
}

\begin{abstract}
This article dealt with the topic of practical training of students in teacher training programmes. Workplace learning represents an important contact between students and the world of work and can have several positive effects. In the text, we presented job shadowing as a possible learning activity that can complement other forms of practical training. The aim of the study was to identify the learning potential of this activity and how it should be structured to achieve this potential. Data were collected from 19 participants, and the qualitative analysis of the text (students' reflections) showed that students gain valuable experience through job shadowing, which helps them to overcome their fears and enables them to enter the workplace with more confidence. In addition to the results of the analysis, the text also provides practical guidance on how the activity should be planned so that students can learn through it.
\end{abstract}

Keywords: learning activity; job shadowing; learning potential; teacher education; workplace learning

\section{Introduction}

Linking theory and practice is an important part of any education, even at tertiary level. While students need to have the opportunity to test theoretical assumptions in a real work environment as part of their studies, it is also useful to be able to translate the insights gained from practice in a professionally supported environment of activities taking place at the faculty. Workplace learning, which is described as an ongoing process of participation, both individual and social, shaped by social, organisational, cultural, and other contextual factors (Hager, 2013), and therefore a suitable way to learn. Interest in workplace learning has grown in recent decades due to the changing nature of work and the recognition of the workplace as a learning environment (Mikkonen et al., 2017). 
The definition developed at the University of Glasgow (Glasgow Caledonian University) suggests that workplace learning defined as:

Achieving planned learning outcomes through experience by performing a job role or function. In contrast, experiential learning is complemented with focused reading, research, or group work at a faculty, which ensures that learning is placed in the context of current theory or practice (Burke et al., 2009, p. 21).

The Foundation Degree Forward (FDF) identified some features of workplace learning for educational purposes which reflect, among other things, Dewey's position on the importance of experiences for learning (Burke et al., 2009).

Maier and Thomas (2013) conducted a longitudinal study among hospitality students, which compared the effects of classroom learning and experiential learning. They summarised the phases of experiential learning according to Kolb's model. For the students, they organised activities that took place in a work environment but were simultaneously supported by learning activities in online classrooms. They found that activities based on the principles of experiential learning offer the students more in-depth learning through integrated real-life experiences, because they take place in a carefully structured environment of activities for which the students are being trained. They highlighted that bridging the gap between theory and practical application of knowledge was of essential importance, since it contributed to students who found it easier to place theoretical knowledge in the context of work or align it with the business context in real life (Maier \& Thomas, 2013). Other authors (Armstrong, 2003; Ruhanen, 2005; Grimwood et al., 2015) also reported several positive effects of this type of learning, especially compared to the so-called "classical learning" which takes place in simulated situations in an educational institution (instead of in the work environment).

Considering the above, workplace learning is at the forefront of pedagogical programmes, but we need to think carefully about how we can offer students different forms of workplace learning over time. We see it as a good opportunity in job shadowing, where students can observe the work of teachers (or other professionals) and learn by observing the actions of others, overcoming fears, and gaining important first practical experience. But even though this is quite an interesting activity, there is little material in the scholarly literature dealing with this topic. Mader et al. (2017) agreed that noting of the published literature review revealed many anecdotal entries in publications by practitioners. Far fewer are the entries in academic journals. Therefore, this activity was also offered as a study activity to explore students' professional interests. Analysis of the transcripts showed that students found the activity informative and relevant to their goals. Despite the somewhat specific methodological approach, the results showed the great potential this type of activity can bring.

\section{Theoretical Framework}

Job shadowing is a form of workplace learning that can be formal or informal and involves gaining work experience (i.e., performing work tasks). The starting 
points of workplace learning come from Lewin's cycle of experiential learning (Kolb, 2015), as Lewin understood learning as an integrated growth process that occurs in four phases. Lewin's model of experiential learning was further developed by Kolb, who introduced learning phases. Today, Kolb's cycle of experiential learning is better known than the cycle envisaged by Lewin, but the starting points of both are cited by authors who study workplace learning. One of them is Raelin (1997) who based his model of workplace learning on Lewin's model and identified four phases of workplace learning (conceptualisation, testing, experience, and reflection).

There are different forms of workplace learning. Kwong et al. (2012) wrote about forms such as field visits, project implementation, simulations, and case studies as part of experiential learning. All the above forms can include practical teaching, exercises, and job shadowing. As far as job shadowing for educational purposes is concerned, this means that the job shadowing activity is carried out by students who are in training for their future profession. At Manchester Metropolitan University job shadowing is defined as an activity as well as an educational programme that enables the student to gain a comprehensive insight into the type of work a person does in a particular workplace. Similarly, Reese (2005) stated that job shadowing is "an opportunity to learn in the workplace, in which students explore work by spending their working day observing an experienced employee at work" (p. 18).

First and foremost, job shadowing is an opportunity to learn about or explore an occupation (or job) that interests the student. However, this does not mean that job shadowing only involves the elements of one's career planning. On the contrary, job shadowing allows the student to see how the knowledge and skills acquired at the faculty can be applied in real-life situations, which the author believes can strengthen the individual's learning (Reese, 2005). In addition to observing and getting to know the work processes, job shadowing also envisages asking relevant questions to get additional information and explanations about what the student ("the shadowee") sees and is interested in. Service et al. (2017) directly linked the job shadowing phases to Kolb's experiential learning model. Accordingly, they suggested that students learn from monitoring the activities they are witnessing, and which represent concrete experiences for them. They learn by observing and listening, as well as through the daily reflection which they perform with their host.

The latter can be associated with thoughtful observation. Afterwards, students will think about the experiences they have gained during job shadowing and, on their basis, conceptualise their knowledge (abstract conceptualisation). When they return to their work environment, they will use what they have gained at the workplace (active experimentation) (Service et al., 2017).

\subsection{Job Shadowing in Relation to Different Types of Practices in Teacher Education}

In the general comparison between teaching practice and job shadowing, we can see that the main difference between them lies in the derivation. In job shadowing, the students have no predetermined tasks to perform during the 
observation. Their task is to act like a shadow, following their host and observing them at work without interfering in the work process (or only in exceptional cases). Job shadowing differs from other forms of practice in that the student observes what a working day (or several) of their host looks like. The primary purpose of the shadowee's briefing with his host is to familiarise himself with the job and the work tasks, and to clarify or reflect on what he has seen. However, this does not mean that the student is not prepared for the job shadowing. Before job shadowing, there must be thorough preparation as part of the activities at the faculty, but this preparation is based on the students' own chosen goals for job shadowing. This is one of the differences with teaching practice, where the objectives are derived from practical training and are the same for all students each year. The preparatory and follow-up job shadowing activities at the faculty are planned in a similar way, due to the reflection results from what the students have seen and experienced and how they felt about it.

It is very important to establish links between faculties and institutions where students can do internships or other activities to learn about the profession for which they are being trained. Real experience in a workplace that is the future work environment for students brings other positive aspects to their studies and their perceptions of their role (Chaaban et al., 2019). Oswald et al. (2017) wrote that the experiences students gain during job shadowing can increase students' engagement and commitment to their studies. This is certainly helped by the fact that students find it easier to understand the knowledge they have acquired at the faculty after the practical experience. Moreover, they can get answers and solve their dilemmas in a professionally supported environment of activities that take place at the faculty. This can be related to the findings of other authors. Wilks and Ross (2014) have developed a job shadowing programme for prospective teachers and believed that job shadowing programmes allow students to link practical knowledge with theoretical assumptions while helping them to overcome fears and giving them the extra confidence they need before starting work. Similarly, Darling-Hammond (2006) noted that:

... beginner teachers with classroom experience find it easier to make sense of the ideas discussed at the faculty, whilst the same teachers see and understand both theory and practice differently if training at the faculty is taking place simultaneously with fieldwork (p. 307).

According to Mader et al. (2017), job shadowing can enrich the experience for the student and create a database of real-time responses to bring local reality into the classroom. Based on the positive aspects of job shadowing, we offered this activity to the students of the second year of the Master's programmes in Pedagogy and Andragogy at the Faculty of Arts of the University of Ljubljana, mainly with the aim that students get an insight into the work they might want to do in the future and thus explore their career options.

\subsection{Purpose and Objectives}

The general aim was to explore how job shadowing was experienced by students who were about to graduate. The aim of the study was also to find out whether job shadowing can also be a suitable learning experience for student teachers, 
and explore what they gain from this kind of study activity. We set four research questions:

1) Was job shadowing also a learning experience for the students?

2) How the students were received by their hosts?

3) What were their main content insights related to job shadowing?

4) What dilemmas and problems they faced during or after job shadowing?

\section{Method}

\subsection{Research Design}

The research design was based on the assumptions of qualitative research, specifically qualitative content analysis (Bryman, 2016). Through the analysis of reflections, we aimed to gain deeper insights into how the activity was experienced by students and to capture nuances in student accounts that would be missed through quantitative approaches. For the further research, we followed the steps suggested by Altheide and Schneider (2013). First, we defined the research questions and familiarised ourselves with the context in which the reflections emerged. For the analysis and extraction of codes and categories, we brought in two researchers who carried out the analysis in two steps. Finally, we compared the identified categories and created a common set of cross-sectional categories. The final step of the research was the preparation of the interpretation.

\subsection{Collecting Data}

Data were collected using qualitative content analysis. We collected analyses from 19 students who wrote a reflection on their study activity after job shadowing. Each student submitted a reflection by summarising the experience based on some pre-determined starting points. These included notes on their motivations for choosing a particular institution and host, as well as their insights, dilemmas and problems encountered during and after their job shadowing.

\subsection{Data Analysis}

The reflections were analysed by two researchers according to the principles of qualitative research (Creswell, 2007). The first step was decomposition, i.e., breaking down or segmenting the text into its component parts to obtain the coding units. By defining the coding units, the parts of the text that were to be further analysed were determined. The coding process was then the central process in formulating the further interpretations. An inductive approach (open coding) was chosen for the coding process, where the codes are determined during the analysis of the text itself. The codes were compared with each other and those that referred to similar phenomena were grouped into categories. The categories were formed by abstracting a common feature from several different descriptions and identifying the links between the individual codes. After analysis, common themes were identified that reflected the content views of the reflections analysed. In the second phase, the categories reflecting the deep content of the reflections were identified for each of the identified themes. 


\subsection{Research Instrument}

The research tool was the students' reflections. These were shorter notes of up to three pages of text. The students submitted the reflections after the activity and described in them the main findings from the job shadowing. The reflections were evaluated in an anonymous form, without the identity of the person who wrote the reflection being established.

\section{Results}

In the analysis of the reflections, the results are presented in the order of the research questions.

\subsection{Motives for Choice}

The students had a free hand in choosing the institutions in which they wanted to do job shadowing, which is very vividly reflected in the records of their motives for selection. Their motives for choosing the institution varied widely. The most frequently expressed motive for choosing a facility was to learn about the profession. In most cases, it was to learn about the profession they would like to pursue in the future. In the reflections, we found that the students were interested in different aspects of getting to know their future profession, from the concrete work tasks that the employees perform to the way they prepare for their work. They wanted to know what problems they encounter in their work and how they solve them. They also wanted to explore very specific areas of work, such as supervising staff training.

Among the motives for choosing a particular institution was interest. Students chose a facility because they were interested in working with certain target groups (e.g., people with special needs, long-term sick children, juvenile offenders, etc.). They were also interested in working in a certain area of the institution (e.g., in the human resources department) or they were curious about how work is done in large (also international) companies. One of the motives for choosing an institution was the desire to introduce work in a home or family business.

Despite the variety of motives put forward, it emerged from most records that students saw job shadowing primarily as an opportunity to learn about a particular occupation or its individual aspects, which is in line with the original idea of job shadowing as understood by other authors. Reese (2005), for example, pointed out that job shadowing is an"... opportunity for workplace learning in which students explore work by spending their working day observing an experienced employee at work" (p. 18).

\subsection{Questions and Dilemmas}

In addition to what the students experienced and saw, they also had some questions and dilemmas that they considered in their reflections. Some dilemmas (and consequently questions) were related to the content of the company's work: why a company works the way it does? , and what are the reasons for this work?. In addition, students had questions and dilemmas related to the use of certain forms. It has been revealed that: 
"Although they try to offer a wide variety of training to meet the needs and wishes of their employees, they still encounter a lot of criticism and dissatisfaction. What surprised me most is that despite the extraordinary effort they put into finding different ways to involve as many staff as possible in training, they still do not have sufficient support from management. How can these two problems be addressed?"

The next aspect and set of dilemmas concerned job shadowing itself, but more importantly how job shadowing should take place. For the students, it was the first time they had encountered job shadowing, so most of them could not imagine how it would work. In this context, the students had various questions (e.g., would they be allowed to participate in the host's activities?, how would the hosts accept them?, would they get along well with the host?, and so on) as well as fears (what impression they would make on the host?, would they just sit and watch what other people do?, how much would they take away from the job shadowing?, and so on).

\subsection{On the Organisation and Preparation for Job Shadowing}

In analysing the reflections, we also noted reflections on the organisation and preparation for job shadowing. Students emphasised the organisation of job shadowing and the importance of preparing questions.

In the first highlighted category, they wrote mainly about the importance of the activities we carried out in relation to job shadowing as part of the elective. Regarding the choice of institutions, they rated the possibility of being able to choose each institution or job themselves as extremely positive:

"The job shadowing experience has really enriched me. It has given me so much in such a short time. It also helped me a lot that I was free to choose the job", "I like the idea that we can choose any job we are interested in...",

as well as discussing all the details of the job shadowing with the host himself:

"I liked the fact that I could agree the exact date of the job shadowing with the company and was not restricted in doing so".

Regarding the preparation for the job shadowing, they also pointed out the preparation of the questions we had formulated in the seminar. They saw the added value mainly in the fact that their preparation of the questions was supervised by the respective institution, which reminded them of the content aspects of the questions as well as the structure of each question. During the preparation, we talked about the different sets of questions (within each set we also prepared very specific questions), which the students found very useful and practical. In this way, we highlighted the aspects they might not have thought of on their own.

For students, a good organisational preparation for the job shadowing can strengthen their sense of independence, as they know what to organise before the job shadowing, how they should behave during the job shadowing and which aspects they should pay special attention to. All these reduce their fear of 
the unknown. Adequate preparation in terms of content has the main effect of ensuring that students experience job shadowing in a structured and in-depth way and benefit as much as possible from the activities.

\section{Discussion}

The discussion presented some important findings on learning activity. Three fundamentally different categories have been identified. The first category refers to the findings related to the content of job shadowing. Students indicated that job shadowing gave them an insight into how the institution/host worked (what their typical working day was like, what their most common work tasks were, how important it was to work with others, how varied the work tasks were, etc.) looks like. Job shadowing also gave them an insight into working with different target groups. In several written reflections, there were comments on the working atmosphere in the company and in this context, the students' reflections on how they would feel working in such a working environment was the second identified category. These were mainly about whether they could imagine themselves working in the observed position, whether they would be able to work in a large company and manage the tasks involved, and the conclusion that they came to because of the job shadowing that they would not want to work in a place where there were bad relationships between employees. In the third aspect, they wrote about what job shadowing was like for them. The activity itself was mainly described as a positive, inspiring, and interesting experience. Such feedback was even recorded in the reflection, where one student wrote that the job shadowing was poorly done mainly because of the host. The students described their experience as "a really good, educational, extremely interesting and useful experience ...", and justified it mainly with reasons such as

"... job shadowing gave me a (real) insight into the world of work; I learned a lot about my host's profession and work; the job shadowing experience will help me in my job search; it will allow me to think anew about my interests and future profession; I will be able to focus on aspects other than teaching practise and so on."

The questions and dilemmas that arise in the job shadowing experience are a good starting point for learning. An experience is not a learning situation if the individual does not have the opportunity to get answers to his/her questions and reflects on his/her dilemmas and experiences. Everything starts with a concrete experience, but it is the attentive observation of what is happening that stimulates the learning process of the individual, because they must find the answers to their questions or dilemmas. They may find it in existing knowledge, or experience may awaken their need to search for new solutions and acquire new knowledge. It is important not to leave the student alone in this process. Part of the learning can take place during the job shadowing itself, when the student raises his/her questions and dilemmas in conversation with his/her host. Otherwise, this part needs to be supported by faculty activities. Even if we do not find concrete answers or solutions to the dilemmas, it is important that we talk to the students about them, put things in a wider context, discuss the theoretical background and so on. Huang (2021) also reports that reflection is an important component of learning. 
Empirical studies have shown that teachers' reflection on their own teaching is an important informal workplace learning activity (Kyndt et al., 2016; Louws et al., 2017). If students are not given the appropriate support and guidance to process and make sense of the experiences gained in this way, we talk about the so-called unprocessed experiences, which, especially if they are not positive, can inhibit or undermine the growth of future experiences (Dewey, 1997). As can be seen from the students' notes, the problems and dilemmas encountered during the job shadowing experience may be related to the content of the experience or to the problems and dilemmas related to the process of the activity. The latter can be somewhat mitigated, especially through good preparation for job shadowing. The job shadowing activity was organised as part of the elective course to familiarise them with the profession they were trained for or any other profession that interested them. According to the records of reflections, we can say that we chose the right activity for this purpose because most of the students reported that job shadowing gave them insights into the segments of the profession or how to perform certain professional tasks.

Through the activity, we also wanted to give students an experience from which they could learn. The records of the reflections (especially in the second and third categories) showed that it was an experience that they found educational. Certainly, the faculty activities contributed to this, as learning has always been at the heart of the activities, we have undertaken in relation to job shadowing as part of the elective. Indeed, we think it is important that students can reflect on their experiences in their studies and discuss their questions and dilemmas together with their peers and the lecturer, who also helps them to (re)conceptualise their knowledge. This is, in our opinion, the most important aspect of this kind of learning.

Similar findings have been made by other authors (Burke et al., 2009; Seward \& Gaesser, 2018). Wilks and Ross (2014) regarded the strength of job shadowing programmes in the fact that students remain engaged in their theoretical and methodological units at the faculty during job shadowing. Moreover, they were able to put the theoretical starting points into practice and reflect on their experiences and observations in discussions with their hosts. However, further reflection and discussion that took place at the faculty helped students to make connections between their observations and conversations with their hosts on lectures and other activities within their studies (Wilks \& Ross, 2014). These authors added that the job shadowing programme not only rethinks the process of professional experience, but also brings about profound changes in the way the different partners in this process connect with each other at different points in the overall professional development of future teachers (Wilks \& Ross, 2014). We cannot write about such applications of our implementation of job shadowing as it was a small-scale implementation. Nevertheless, we received some feedback from the hosts who indicated that the job shadowing (but especially the interviews with the shadowees) made them reflect on some areas of their own work while answering the students' questions. 


\section{Implication for Practice}

In the paper, we presented job shadowing as a learning experience that can be offered to students during their studies. Based on the theoretical starting points and the analysis of the considerations presented, we come to the following recommendations:

- Job shadowing can be an appropriate activity for students preparing for educational careers. It is very important that we plan the activity well and integrate it meaningfully with the activities that take place in the faculty as part of the study programme.

- Job shadowing and student teaching practise are based on the same starting point, but we see several differences between job shadowing and teaching practice that indicate that the two activities cannot be equated. In job shadowing, the student has no predetermined tasks to perform during the observation. His/her task is to accompany the hosts and observe them at work without interfering in the work process (or only in exceptional cases). In addition, during job shadowing, the student observes what a working day of their host looks like. The briefing of the shadowee with his/her host serves primarily to get to know the job and the work tasks as well as to clarify or reflect on what has been seen. The preparation is also different as it is based on the students' own chosen goals for job shadowing. This is one of the differences with teaching, where the objectives come from practical training and are the same for all students in a year. Students recognised the difference between the two activities and highlighted it in their reflections.

- Job shadowing is not an activity that could in any way replace the goals achieved through various forms of practical training. In summary, we see it more as an opportunity through which students can get to know the profession better at the beginning or end of their studies. If we offer students this activity at the beginning of their studies, it can help them identify with the profession they are studying. This can not only have a positive impact on the development of their professional identity, but also increase their motivation for the studies themselves, as job shadowing gives them an insight into how the knowledgethey have gained at the faculty translates into their daily work (Radovan \& Makovec, 2015).

A limitation of the study could be the lack of quantitative results on student satisfaction with job shadowing to support the findings of the qualitative analysis. For future research, it would be useful to explore and investigate this area of practical training in a structured way, which could also help to make the subject more scientific.

\section{Conclusion}

We offered the job shadowing activity to students who were graduating. In their reflections, the students wrote that during the job shadowing, they thought about their careers. Some of them began to think about their career choices in ways they had not before. This suggests that job shadowing influenced their perception of the profession or individual job roles. Job shadowing was thus a learning experience that initially raised questions and dilemmas for the students, 
but later (and especially through reflection) contributed to clearer thinking about the profession and their perception of it.

On this basis, we believe that job shadowing can become an experience from which learning emerges. As such, it is an appropriate activity for students preparing for a career in education. However, it is true of this activity (and other experiences) that it only has learning potential if it is meaningful. It is important that the teacher plays his/her role in preparing or reflecting after the job shadowing activity has been completed, otherwise, job shadowing becomes a mere visit to a work environment.

\section{References}

Altheide, D. L., \& Schneider, C. J. (2013). Qualitative media analysis (2nd ed.). Sage Publications. https://doi.org/10.4135/9781452270043

Armstrong, E. K. (2003). Applications of role-playing in tourism management teaching: An evaluation of a learning method. Journal of Hospitality, Leisure, Sport $\mathcal{E}$ Tourism Education, 2(1), 5-16. https:/ / doi.org/10.3794/johlste.21.24

Bryman, A. (2016). Social research methods. Oxford University Press.

Burke, L., Marks-Maran, D. J., Ooms, A., Webb, M., \& Cooper, D. (2009). Towards a pedagogy of work-based learning: Perceptions of work-based learning in foundation degrees. Journal of Vocational Education $\mathcal{E}$ Training, 6(1), 15-33. https:/ / doi.org/10.1080/13636820902819917

Chaaban, Y., Du, X., \& Ellili-Cherif, M. (2019). Influence of the practicum experience on student teachers' beliefs about their role in EFL classrooms. International Journal of Learning, Teaching and Educational Research, 18(9), 78-95. https://doi.org/10.26803/ijlter.18.9.4

Creswell, J. W. (2007). Qualitative inquiry and research design: Choosing among five approaches (2 ${ }^{\text {nd }}$ ed.). Sage Publications.

Darling-Hammond, L. (2006). Constructing 21 st century teacher education. Journal of Teacher Education, 57(3), 300-314. https:/ / doi.org/10.1177/0022487105285962

Dewey, J. (1997). Experience $\mathcal{E}$ education. Touchstone.

Grimwood, B. S. R., Arthurs, W., \& Vogel, T. (2015). Photo essays for experiential learning: Toward a critical pedagogy of place in tourism education. Journal of Teaching in Travel $\mathcal{E}$ Tourism, 15(4), 362-381. https:// doi.org/10.1080/15313220.2015.1073574

Hager, P. (2013). Theories of workplace learning. In M. Malloch, L. Cairns, K. Evans, \& B. O'Connor (Eds.), The SAGE handbook of workplace learning (pp. 17-32). Sage Publications.

Huang, X. (2021). Striving for better teaching and student creativity development: Linking informal workplace learning and teaching for creativity. Thinking Skills and Creativity, 41,100889. https://doi.org/10.1016/j.tsc.2021.100889

Job Shadowing Guidelines (n.d.). Human resources organisation development training $\mathcal{E}$ diversity. Manchester Metropolitan University. https://www2.mmu.ac.uk/media/mmuacuk/content/documents/humanresources/a-z/guidance-procedures-andhandbooks/Job_Shadowing_Guidelines.pdf

Kolb, D. (2015). Experiential learning: Experience as the source of learning and development ( $2^{\text {nd }}$ ed.). Pearson Education.

Kyndt, E., Gijbels, D., Grosemans, I., \& Donche, V. (2016). Teachers' everyday professional development: Mapping informal learning activities, antecedents, 
and learning outcomes. Review of educational research,86(4), 1111-1150. https://doi.org/10.3102/0034654315627864

Kwong, C. C. Y., Thompson, P., \& Cheung, C. W. M. (2012). The Effectiveness of social business plan competitions in developing social and civic awareness and participation. Academy of Management Learning \& Education, 11(3), 324-348. https://doi.org/10.5465/amle.2011.0007a

Louws, M. L., Meirink, J. A., van Veen, K., \& van Driel, J. H. (2017). Teachers' selfdirected learning and teaching experience: What, how, and why teachers want to learn. Teaching and teacher education, 66, 171-183. https:// doi.org/10.1016/j.tate.2017.04.004

Mader, F. H., Mader, D. R., \& Alexander, E. C. (2017). Job shadowing experiences as a teaching tool: A new twist on a tried and true technique. Atlantic Marketing Journal, 5(3), 113-120.

Maier, T. A., \& Thomas, N. J. (2013). Hospitality leadership course design and delivery: A blended-experiential learning model. Journal of Hospitality $\&$ Tourism Education, 25(1), 11-21. https://doi.org/10.1080/10963758.2013.777585

Mikkonen, S., Pylväs, L., Rintala, H., Nokelainen, P., \& Postareff, L. (2017). Guiding workplace learning in vocational education and training: A literature review. Empirical Research in Vocational Education and Training, 9(1), 1-22. https://doi.org/10.1186/s40461-017-0053-4

Oswald, R.G., Alderman, A. L., \& Willmering, P. (2017). Short-term job shadowing experience benefits for undergraduate rehabilitation students. Australian Journal of Rehabilitation Counselling. 23(2), 79-89. https:// doi.org/10.1017/jrc.2017.2

Radovan, M., \& Makovec, D. (2015). Relations between students' motivation, and perceptions of the learning environment. Center for Educational Policy Studies Journal, 5(2), 115-138. https:// doi.org/10.26529/cepsj.145

Raelin, J. A. (1997). A model of worked based learning (WBL). Organization Science, 8(6), 563-578. https://doi.org/10.1287/orsc.8.6.563

Reese, S. (2005). Exploring the world of work through job shadowing. Techniques: Connecting Education and Careers, 80(2), 18-23.

Ruhanen, L. (2005). Bridging the divide between theory and practice: Experiential learning approaches for tourism and hospitality management education. Journal

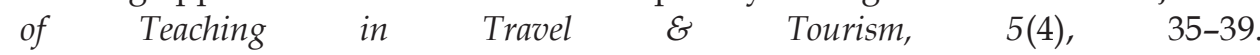
https://doi.org/10.1300/J172v05n04_03

Service, B., Dalgic, G. E., \& Thornton, K. (2017). Benefits of a shadowing/mentoring intervention for New Zealand school principals. Professional Development in Education, 44(4), 507-520. https://doi.org/10.1080/19415257.2017.1378705

Seward, K., \& Gaesser, A. H. (2018). Career decision-making with gifted rural students: Considerations for school counsellors and teachers. Gifted Child Today, 41(4), 217-225. https:// doi.org/10.1177/1076217518786986

Shortt, G. B. (1987). A case study of the relationship between cognitive style and experiential learning in hospitality management education. Journal of Hospitality \& Tourism Research, 11(1), 1-18. https://doi.org/10.1177/109634808701100302

Wilks, J., \& Ross, K. (2014). Shadowing, »The most valuable thing you can do«: Threading informal classroom experiences into secondary pre-service teacher education. Teacher Education Quarterly, 41(2), 93-106. 